Um espirito na framboesa

Tradução do conto Uno spirito in un lampone, de Iginio Ugo Tarchetti

Rafael Ferreira da Silva

Davi de Sousa Barbosa

\title{
Um espírito na framboesa
}

Tradução do conto Uno spirito in un lampone, de Iginio Ugo Tarchetti

\author{
Rafael Ferreira da Silva \\ Universidade Federal do Ceará \\ rafael.ferreira@letras.ufc.br \\ Davi de Sousa Barbosa \\ Universidade Federal do Ceará \\ davisouzabarbosa@hotmail.com
}

Em 1854, um acontecimento surreal deixou toda a humilde população de um pequeno vilarejo da Calábria chocada e aterrorizada.

Tentarei contar, com a maior exatidão que me for possível, essa aventura sobrenatural, embora eu tenha consciência de que é algo extremamente difícil expô-la em toda a sua verdade e com todos os seus detalhes mais interessantes.

O jovem Barão de B. - lamento que uma promessa formal me proíba de contar o seu nome - tinha herdado havia poucos anos a rica e extensa propriedade do seu avô paterno, situada em uma das regiões mais encantadoras da Calábria. O jovem herdeiro jamais havia se afastado daquelas montanhas tão ricas de pomares e de natureza selvagem; na velha moradia da família, que há muito tempo tinha sido um castelo feudal fortificado, havia aprendido com o professor de casa os primeiros conhecimentos da escrita, e os nomes de três ou quatro clássicos latinos dos quais sabia citar, se necessário, alguns trechos bem conhecidos. Como todos os sulistas, tinha paixão por caça, cavalos e amores três paixões que frequentemente vão lado a lado como os cavalos das carruagens dos correios. Poderia satisfazê-las com o seu talento, mas nunca nem tinha se preocupado com isso; nem nunca tinha imaginado que além dos cumes irregulares dos Apeninos houvesse outras cidades, outras pessoas e outras paixões. 
Mesmo porque, como a sabedoria não é um dos requisitos indispensáveis para a felicidade (na realidade, é bem o oposto), o jovem Barão de B. sentia-se perfeitamente feliz com a sua humilde seleção de versos decorados; e não eram menos felizes ao seu lado os seus empregados, as suas mulheres, os seus cães de caça e os seus doze súditos de farda verde com o brasão da família, encarregados de ir à frente e atrás da sua carruagem de gala em circunstâncias solenes.

Havia um único fato triste que, alguns meses antes da época em que se passa a nossa história, tinha causado muita tristeza a uma família encarregada dos serviços da casa, alterando a tradicional paz do castelo. Uma camareira do Barão, uma moça conhecida por ter tido pequenos romances com alguns empregados, havia desaparecido repentinamente do vilarejo; todas as buscas tinham sido em vão; e apesar de muitas suspeitas recaírem sobre um dos guardas-florestais - um jovem de índole violenta que havia tido uma paixão não correspondida pela criada. Essas suspeitas eram, de fato, imprecisas e infundadas, que o seu comportamento calmo e seguro foi mais que suficiente para inocentá-lo.

Esse desaparecimento misterioso, que levava a crer que se tratasse de um crime, havia entristecido profundamente o honesto Barão de B.; mas pouco a pouco ele foi esquecendo, ocupando os seus pensamentos com o amor e com a caça: a alegria e a tranquilidade retornaram ao castelo; os guardas de farda verde voltaram a ocupar os corredores; mas não haviam se passado nem dois meses do ocorrido e nem o Barão, nem alguns empregados lembravam-se do desaparecimento da jovem.

Era o mês de novembro.

Certa manhã, o jovem Barão de B. acordou assustado com um pesadelo, saiu da cama, escancarou as janelas, e, vendo que o céu estava limpo e que seus cães de caça andavam tristes pelo pátio, arranhando o portão para sair, disse: 
"Quero ir caçar. Sozinho. Estou vendo lá longe uns pombos selvagens que pousaram na plantação e espero que paguem a conta com as penas". Tendo se decidido, terminou de se vestir, calçou suas botas impermeáveis, colocou o fuzil a tiracolo, despediu-se dos dois guardas de farda verde que sempre o acompanhavam e saiu acompanhado de todos os seus cães de caça, que se enfiavam entre suas pernas acariciando as suas botas com a cauda e balançavam a cabeça, fazendo barulho com as orelhas que batiam.

O Barão de B. partiu diretamente para o lugar onde havia visto pousarem os pombos selvagens. Era época de semeadura, e nos campos recém-arados não se via nem arbusto, nem grama. As chuvas do outono haviam encharcado tanto o terreno, que o Barão afundava até o joelho, vendo a hora de perder uma bota. Além disso, os cães, não acostumados com aquele tipo de caça, estragavam toda a estratégia do caçador e os pombos haviam espalhado as suas sentinelas, exatamente como um bom batalhão da velha guarda imperial faria.

Apesar de estar irritado com essa esperteza, o Barão de B. continuou a persegui-los ainda mais obstinado, mas, mesmo assim, não conseguiu acertar nenhum. Estava exausto e com muita sede quando viu ali perto um exuberante arbusto carregado de framboesa madura.

- Estranho! - disse o Barão. - Uma framboeseira justo aqui... e quantos frutos! Como estão bonitos e maduros!

Abaixou o fuzil, colocando-o ao seu lado, e sentou-se; e arrancando as framboesas uma a uma, cujos gomos vermelhos estavam graciosamente prateados pelo orvalho, matou, da melhor forma possível, a sede que começava a castigá-lo.

Permaneceu assim sentado por meia hora, quando se deu conta de que estavam acontecendo algumas coisas estranhas com ele.

O céu, o horizonte e o campo já não lhe pareciam os mesmos; isto é, não é que tinham, de fato, mudado, mas não os estava vendo com a mesma sensação 
de uma hora atrás; ou, como se diz por aí, não os estava mais vendo com os mesmos olhos.

No meio dos seus cães havia alguns que achava que nunca tinha visto, mas pensando bem, os conhecia; de qualquer modo, observava e acariciava a todos com o máximo respeito de sempre: parecia, de certa forma, que ele não era o dono, e quase duvidando, experimentou chamá-los: Azor, Fido, Aloff! Os cães chamados se aproximaram prontamente, abanando a cauda.

- Menos mal, disse o Barão, os meus cães ainda parecem ser exatamente os meus cães... Mas é estranha esta sensação que sinto na cabeça, este peso... $\mathrm{E}$ o que são estes desejos estranhos que estou sentindo, estas vontades que nunca tive, esta espécie de confusão e de dualidade que está tomando todos os meus sentidos? Estou ficando louco? Vejamos, vamos reorganizar as nossas ideias... As nossas ideias! Isso, exatamente... porque sinto que estas ideias não são todas minhas. Porém... é fácil organizá-las! Não é possível, sinto que algo está embaralhado no cérebro, isto é... quero dizer... está diferente de como estava antes... algo desnecessário, excessivo; uma coisa que quer se instalar na minha cabeça, que não machuca, mas que pressiona e incomoda, batendo na parede do crânio... Pareço um homem duplo. Um homem duplo! Que estranho! Mas pelo menos... sim, sem dúvidas... agora eu entendo como se pode ser um homem duplo.

Gostaria de saber por que essas flores encharcadas pela chuva, que eu nunca observei na minha vida, agora me parecem tão belas e atraentes... Que cores vivas, que forma simples e graciosa! Vamos fazer um buquê com essas anêmonas.

E o Barão, esticando a mão sem se levantar, colheu três ou quatro, que maravilha! Colocou no peito como fazem as mulheres. Mas ao aproximar a mão de si mesmo sentiu uma sensação ainda mais estranha; queria aproximar a mão, e ao mesmo tempo queria esticá-la de novo; o braço movido por duas vontades 
opostas, mas igualmente potentes, permaneceu naquela posição quase paralisado.

- Meu Deus! - disse o Barão; e, fazendo um grande esforço, saiu daquele estado de rigidez, e logo olhou atentamente para a sua mão, observando se havia algo quebrado ou rompido.

Pela primeira vez ele observou que as suas mãos eram pequenas e perfeitas, que os dedos eram robustos e arredondados, que as suas unhas descreviam uma elipse perfeita; e ficou observando com um prazer incomum; olhou para os pés e percebendo-os pequenos e finos, apesar da forma um pouco rude de suas botas, ficou satisfeito com eles e sorriu.

Naquele momento, um bando de pombos levantou voo em um campo vizinho e foi em sua direção. O Barão agiu rápido, pegou o fuzil, engatilhou, mas... que espantoso! Naquele momento percebeu que tinha medo do seu fuzil, que o estrondo do disparo poderia assustá-lo; ficou parado e deixou a arma cair de sua mão, enquanto uma voz interna lhe dizia: Que belos pássaros! Como são belas as penas das suas asas! Acho que são pombos selvagens...

— Que inferno! Exclamou o Barão levando a mão até a cabeça, eu não estou mais me entendendo... ainda sou eu ou não sou mais eu? Ou sou eu e um outro ao mesmo tempo! Quando foi que eu tive medo de atirar com o meu fuzil?! Quando foi que eu senti pena desses malditos pombos que comem as sementes plantadas?! Os campos semeados! Mas... quer saber, acho que essas plantações aqui já não são minhas... Basta, basta, vamos voltar para o castelo. Eu devo estar com febre e vai passar quando eu me deitar.

E fez como fosse se levantar. Mas, naquele instante, uma outra vontade que parecia existir dentro dele o forçou a permanecer na posição de antes, como se quisesse lhe dizer: "Não, vamos ficar sentados mais um pouco".

O Barão sentiu que concordava de bom grado com esta vontade, visto que da continuação da estrada que contornava a plantação vinha um grupo de 
jovens trabalhadores que voltavam para o vilarejo. Ele os observou com um certo tipo de interesse e desejo que não sabia o que era; viu que havia alguns bem bonitos; e quando passaram por ele e o cumprimentaram, ele respondeu inclinando a cabeça com muita vergonha, e percebeu que estava enrubescido como uma mocinha. Então, percebeu que não tinha mais nenhuma dificuldade para levantar, e se levantou. Quando ficou de pé, sentiu-se mais leve que o habitual: as suas pernas pareciam ora mais pesadas ora mais leves; os seus movimentos estavam mais graciosos que o normal, embora fossem os mesmos movimentos de antes, de fato, e achasse que estava caminhando, gesticulando e se movendo como sempre havia feito antes.

Tentou colocar o fuzil a tiracolo, mas teve o mesmo medo de antes, que foi melhor levá-lo na mão, deixando um pouco afastado do corpo, igual a um garotinho assustado.

Chegando a um ponto aonde a estrada se bifurcava, ficou indeciso sobre por qual das duas estradas deveria seguir para voltar para o castelo. Todas as duas serviam, mas ele estava acostumado a ir sempre pela mesma: agora queria ir por uma e ao mesmo tempo queria ir pela outra: tentou se mover, mas sentiu a mesma sensação que havia sentido pouco antes: as duas vontades que pareciam dominá-lo, agindo sobre ele com a mesma força, tinham se neutralizado, invalidando as duas ações: ele permaneceu imóvel na estrada petrificado, como se estivesse tendo um ataque de catalepsia. Depois de um certo tempo, percebeu que aquele estado de rigidez havia passado, que a sua hesitação havia desaparecido, e voltou pela estrada que sempre costumava seguir.

Não havia dado nem cem passos e passou pela mulher do magistrado, a qual o cumprimentou educadamente.

- Desde quando - disse o Barão de B. - que a mulher do magistrado me cumprimenta? Então se lembrou de que ele era o Barão de B. e era um 
conhecido íntimo daquela senhora, e se admirou de ter feito essa pergunta a si mesmo.

Um pouco mais adiante encontrou uma velha que passava arrancando ramos secos ao longo da cerca de arbustos.

- Bom dia, Caterina - abraçando-a e dando-lhe um beijo na bochecha - Tudo bem? Tem recebido notícias do seu sogro?

- Oh! Excelência... quanta gentileza - exclamou a velha, meio assustada com a estranha familiaridade do Barão, — vou lhe contar...

Mas o Barão a interrompeu dizendo: - Por caridade, olhe bem para mim e me diga: Ainda sou eu? Ainda sou o Barão de B.?

— Oh, senhor! — disse ela.

Ele não ficou para ouvir a resposta e prosseguiu no seu caminho, enfiando as mãos no cabelo gritando: - Eu estou louco, eu estou louco!

A todo instante sentia vontade de parar pela rua para contemplar objetos e pessoas que nunca the haviam despertado o mínimo interesse e os via com uma perspectiva completamente diferente de antes. As belas camponesas que ficavam arando os campos com os vestidos levantados acima dos joelhos não despertavam nele mais interesse algum, elas pareciam banais, rudes e desleixadas. Lançando por acaso o olhar para os seus cães que iam à sua frente com o focinho baixo e com a cauda balançando, disse: "Olha só! Visir, que só tinha dois meses, agora parece ter oito completos, já está no meio dos cães escolhidos".

Faltavam poucos passos para chegar ao castelo, quando encontrou alguns de seus empregados que passeavam conversando ao longo da estrada, e que estranho! Os via em dobro; acontecia o mesmo fenômeno óptico de quando se converge as duas pupilas para um único centro, obtendo uma visão cruzada; porém ele compreendia que as causas desse fenômeno eram completamente diferentes disso; já que os via em dobro, mas não se pareciam 
totalmente em sua duplicidade; os via como se fossem duas pessoas dentro dele que enxergavam pelos mesmos olhos.

E esta estranha duplicidade começou, a partir daquele momento, a se estender por todos os seus sentidos; enxergava em dobro, sentia em dobro, tocava em dobro; e - uma coisa ainda mais surpreendente! Pensava em dobro. Isto é, uma mesma sensação despertava nele duas ideias, e estas duas ideias eram conduzidas por duas forças diferentes de raciocínio, e julgadas por duas consciências diferentes. Parecia, por assim dizer, que fossem duas vidas na vida dele, mas duas vidas opostas, separadas, de natureza diferente; duas vidas que não podiam se unir e que lutavam para dominar os seus sentidos - daí a duplicidade das suas sensações.

Foi por isto que, vendo os seus empregados, ele reconheceu perfeitamente que eram os seus empregados, mas cedendo a um impulso bem forte, não teve como não se aproximar de um deles, abraçá-lo com afeto e lhe dizer: - Oh! Querido Francesco, é um prazer revê-lo, tudo bem? Como vai o nosso Barão? - e sabia muito bem que ele era o Barão. - Diga a ele que me verá daqui a pouco no castelo.

Os empregados se afastaram assustados; e aquele que havia sido abraçado dizia para si mesmo: - Eu quebraria a minha cabeça para saber se foi realmente o Barão que falou comigo ou não. Eu já ouvi outras vezes aquelas palavras... não sei... mas aquela expressão... aquele tom... aquele abraço... com certeza, essa não foi a primeira vez que fui abraçado daquela forma. E outra... o meu nobre senhor nunca me deu a honra de tanta familiaridade.

Poucos passos adiante, o Barão de B. viu uma pérgola em um canto do jardim erguida de tal maneira que quando está coberta de folhas torna-se inacessível aos olhos dos curiosos. Ele não conseguiu resistir ao desejo de entrar ali, embora existisse nele uma outra vontade que o incitava a se apressar em 
direção ao castelo. Cedeu ao primeiro impulso, e assim que se sentou sob a pérgola sentiu acontecer dentro de si um fenômeno ainda mais curioso.

Formou-se nele uma nova consciência: toda a trama de um passado nunca visto revelou-se diante dos seus olhos: memórias doces e puras, com as quais ele não poderia ter alimentado a sua vida, vieram para bagunçar docemente a sua alma. Eram memórias de um primeiro amor, de uma primeira culpa; mas de um amor mais gentil e mais elevado do que ele tinha experimentado, de uma culpa mais doce e mais generosa do que ele tinha sentido. A sua mente pairava em um mundo ignorado de afetos, percorria regiões nunca vistas, evocava ternuras nunca conhecidas.

Apesar de todo esse conjunto de recordações, esta nova existência que tinha vindo para se juntar a ele não bagunçava e nem confundia as memórias especiais de sua vida. Uma linha imperceptível separava as duas consciências.

O Barão de B. passou um certo tempo sob a pérgola, depois sentiu vontade de se apressar em direção ao vilarejo. Com as duas vontades agindo em sintonia em relação a isso, sentiu um impulso tão forte que não foi capaz de manter o seu passo habitual e foi forçado a correr impetuosamente.

As duas vontades, a partir daquele instante, começaram a se conhecer e a dominá-lo com forças iguais. Quando agiam de comum acordo, os movimentos da sua pessoa eram precipitados, impetuosos, violentos; se uma se anulava, eram regulares; se eram contrárias, os movimentos se neutralizavam e causavam uma paralisia que se prolongava até que a vontade mais potente predominasse.

Enquanto ele corria em direção ao castelo, um dos seus empregados o viu, e temendo alguma desgraça, chamou-o pelo nome. O Barão quis parar, mas não conseguiu; diminuiu o passo e parou, mas só por alguns instantes, então veio outro espasmo, deu um salto. Prosseguiu e retrocedeu saltitando, que 
parecia estar possuído, e prevaleceu a vontade de continuar a corrida até o vilarejo.

$\mathrm{O}$ vilarejo não parecia mais aquele, parecia que ele tinha estado ausente por muitos meses, viu que o campanário da igreja havia sido reformado de pouco, e embora soubesse daquilo, mesmo assim parecia não saber.

Ao longo da estrada encontrou muitas pessoas que, surpresas em vê-lo correr, observavam-no abismados. Ele acenava para todos com o chapéu, embora entendesse que não devia; e as pessoas lhe respondiam com as suas boinas, maravilhados com tanta cortesia. Mas o que parecia mais estranho era que todas aquelas pessoas consideravam meio familiar aquela sua corrida, aquele seu cumprimentar; e parecia que eles haviam interpretado, intuído, compreendido alguma coisa em seus atos, mas não sabiam o que era. Estavam, porém, assustados e preocupados com aquilo.

Chegando ao castelo, ele parou; entrou nas antecâmaras; beijou as suas empregadas uma a uma, apertou a mão dos guardas de farda verde e se lançou ao pescoço de um deles, acariciando-o com muita delicadeza e dizendo palavras de paixão e de afeto.

Vendo aquilo, as empregadas e os guardas fugiram correndo e gritando para que se trancassem em seus aposentos.

Então o Barão de B. subiu aos outros andares, passou por todos os cômodos do castelo, e chegando ao seu quarto, jogou-se na cama, e disse: "Eu venho dormir com o senhor, Barão." Naquela pausa de repouso, as suas ideias se reordenaram, ele se lembrou de tudo aquilo que lhe havia acontecido durante as últimas duas horas, e ficou apavorado; mas foi só por um instante - ele cedeu rapidamente ao domínio daquela vontade que o conduzia como queria.

Tornou a repetir para si as palavras que havia dito pouco tempo antes: "Eu venho dormir com o senhor, Barão." E algumas novas memórias apareceram na sua alma; eram memórias em dobro, isto é, as memórias das 
impressões que um mesmo fato deixa em dois espíritos diferentes, e ele acolhia estas duas impressões. Porém estas memórias não eram iguais àquelas que já tinha tido sob a pérgola; aquelas eram simples, estas, complexas; aquelas deixavam vazia, neutra, suscetível uma parte da alma; estas a ocupavam por completo: e visto que eram recordações de amor, ele compreendeu naquele momento o que seria a grande união, a imensa complexidade do amor, o qual, estando nas leis inexoráveis da vida, um sentimento dividido entre dois, só pode ser entendido por cada um pela metade. Era a fusão plena e completa de dois espíritos, fusão na qual o amor é apenas um desejo, e as doçuras do amor, um reflexo, um eco, um sonho com aquelas doçuras. Não poderia explicar de forma menos confusa o estado único em que se encontrava.

Ficou assim por cerca de uma hora, quando percebeu que aquele fervor estava amenizando, e que as duas vidas que pareciam animá-lo estavam se separando. Levantou-se da cama, passou as mãos no rosto como que tirando algo leve... um véu, uma sombra, uma pluma; e sentiu que o tato não era mais o mesmo; percebeu que os seus traços tinham mudado, e sentiu a sensação de estar acariciando o rosto de uma outra pessoa.

Correu para se olhar no espelho que havia ali perto. Que coisa estranha! Não era mais ele; quero dizer, via, sim, a sua imagem refletida, mas a via como se fosse a imagem de uma outra pessoa, via duas imagens em uma. Sob a epiderme transparente da sua pessoa revelava-se uma segunda imagem com perfis esfumaçados, indefinidos, conhecidos. E isso lhe parecia naturalíssimo, pois sabia que na sua unidade havia duas pessoas, que era um, mas que também eram dois ao mesmo tempo.

Afastando o olhar do espelho, viu na parede oposta um velho retrato seu em tamanho natural, e disse: "Ah! Este é o senhor Barão de B.... Como envelheceu!" E voltou a contemplar-se no espelho. 
Então a visão daquela figura lhe fez recordar que havia no corredor do castelo uma imagem parecida com aquela que havia visto pouco antes no seu reflexo no espelho, e se sentiu dominado por uma vontade invencível de vê-la novamente. Apressou-se em direção ao corredor.

Algumas empregadas que passavam naquele momento ficaram ainda mais espantadas do que antes, e fugiram correndo para chamar os guardas de farda verde que estavam reunidos na antecâmara, decidindo o que fazer.

Enquanto isso, um bom número de curiosos tinha se aglomerado no pátio do castelo: a notícia das loucuras cometidas pelo Barão tinha sido espalhada pelo vilarejo em poucos instantes. Logo correram em seu socorro o médico, o magistrado e outras pessoas importantes da cidade.

Ficou decidido de entrarem no corredor. O pobre Barão foi encontrado de pé diante do retrato de uma jovem - aquela mesma que havia desaparecido do castelo meses atrás - em um estado de euforia nervosa impossível de se definir. Ele parecia estar em meio a um ataque violento de epilepsia, toda a sua vitalidade parecia se concentrar naquela tela, parecia haver dentro dele algo que queria se libertar do seu corpo, que queria sair dele para entrar na imagem daquele quadro. Ele a observava inquieto, e fazia movimentos esquisitos em direção a ela, como se estivesse sendo atraído por uma força arrebatadora.

Mas o fato mais assustador era que os seus traços pareciam estar se transformando. Quanto mais ele olhava para a tela, mais parecia adquirir uma outra expressão. Todos ali reconheciam nele o Barão de B., mas, ao mesmo tempo, via nele uma semelhança com a imagem reproduzida no quadro. A multidão reunida no corredor foi acometida de um pânico indescritível. Mas o que eles estavam vendo? Não sabiam: sentiam-se como se estivessem diante de algo sobrenatural. 
Ninguém ousava se aproximar. Ninguém se mexia. Um medo insuperável tinha tomado conta de cada um deles, que sentiam um arrepio de terror correndo por todo o corpo...

Conforme o Barão aproximava-se do quadro, a sua euforia aumentava, os seus traços se modificavam e a sua imagem se assemelhava mais e mais à da jovem... e algumas pessoas já pareciam querer explodir em um grito de horror, embora um medo misterioso mantivesse todos mudos e paralisados, quando, de repente, uma voz se elevou inesperadamente da multidão: - Clara! Clara!

Aquele grito quebrou o encanto. "Sim, Clara! Clara!" - as pessoas reunidas no corredor repetiram concordando, apertando-se umas às outras na porta, dominadas por um terror ainda maior, e aquele era o nome da jovem desaparecida do castelo, cuja imagem estava reproduzida na tela.

Mas com aqueles gritos, o Barão de B. afastou-se do quadro lançando-se em direção à multidão gritando: “O meu assassino, o meu assassino!". A multidão se afastou e se dividiu. Um homem estava no chão desmaiado - o mesmo que havia gritado - o jovem guarda-florestal sobre quem recaíam as suspeitas do desaparecimento misterioso de Clara.

$\mathrm{O}$ Barão de $\mathrm{B}$. foi contido à força pelos seus guardas de farda verde. $\mathrm{O}$ guarda-florestal, retomando a consciência, confessou espontaneamente ao magistrado ter matado a jovem em um momento de ciúme excessivo, e revelou tê-la enterrado em uma plantação, precisamente naquele lugar onde, poucas horas atrás, havia visto o Barão desafortunado sentar-se e comer as framboesas.

Foi dada rapidamente ao Barão de B. uma forte dose de emético que o fez vomitar as bagas não digeridas, libertando-o do espírito da jovem.

O seu cadáver, cujas raízes da framboeseira nasciam de seus seios, foi desenterrado e recebeu um sepultamento cristão no cemitério.

O guarda-florestal, julgado no tribunal, foi condenado a doze anos de trabalho forçado. 
Um espirito na framboesa

Tradução do conto Uno spirito in un lampone, de Iginio Ugo Tarchetti

Rafael Ferreira da Silva

Davi de Sousa Barbosa

Em 1865, eu o conheci na penitenciária de Cosenza, que eu tinha ido visitar. Faltavam-lhe ainda dois anos para cumprir a pena; e foi dele mesmo que ouvi esta história surreal. 
Um espirito na framboesa

Tradução do conto Uno spirito in un lampone, de Iginio Ugo Tarchetti

Rafael Ferreira da Silva

Davi de Sousa Barbosa

\section{UNO SPIRITO IN UN LAMPONE}

Nel 1854 un avvenimento prodigioso riempì di terrore e di meraviglia tutta la semplice popolazione d'un piccolo villaggio della Calabria.

Mi attenterò a raccontare, con quanta maggior esattezza mi sarà possibile, questa avventura meravigliosa, benchè comprenda essere cosa estremamente difficile l'esporla in tutta la sua verità e con tutti i suoi dettagli più interessanti.

Il giovine barone di B. - duolmi che una promessa formale mi vieti di rivelarne il nome - aveva ereditato da pochi anni la ricca ed estesa baronia del suo avo paterno, situata in uno dei punti più incantevoli della Calabria. Il giovine erede non si era allontanato mai da quei monti sì ricchi di frutteti e di selvaggiume; nel vecchio maniere della famiglia, che un tempo era stato un castello feudale fortificato, aveva appreso dal pedagogo di casa i primi erudimenti dello scrivere, e i nomi di tre o quattro classici latini di cui sapeva citare all'occorrenza alcuni distici ben conosciuti. Come tutti i meridionali aveva la passione della caccia, dei cavalli e dell'amore - tre passioni che spesso sembrano camminare di conserva come tre buoni puledri di posta - potevale appagare a suo talento, nè s'era mai dato un pensiero di più; non aveva neppur mai immaginato che al di là di quelle creste frastagliate degli Appennini vi fossero degli altri paesi, degli altri uomini e delle altre passioni.

Del resto siccome la sapienza non è uno dei requisiti indispensabili alla felicità — anzi parci l'opposto — il giovine barone di B. sentivasi perfettamente felice col semplice corredo dei suoi distici; e non erano meno felici con lui i suoi domestici, le sue donne, i suoi limieri, e le sue dodici livree verdi incaricate di precedere e seguire la sua carrozza di gala nelle circostanze solenni.

Un solo fatto luttuoso aveva, alcuni mesi prima dell'epoca a cui risale il nostro racconto, portata la desolazione in una famiglia addetta al servigio della 
casa e alterate le tradizioni pacifiche del castello. Una cameriera del barone, una fanciulla che si sapeva aver tenute tresche amorose con alcuni dei domestici, era sparita improvvisamente dal villaggio; tutte le ricerche erano riuscite vane; e benchè pendessero non pochi sospetti sopra uno dei guardaboschi — giovine d'indole violenta che erane stato un tempo invaghito, senza esserne corrisposto — questi sospetti erano poi in realtà così vaghi e così infondati, che il contegno calmo e sicuro del giovane era stato più che sufficiente a disperderli.

Questa sparizione misteriosa che pareva involgere in sè l'idea di un delitto, aveva rattristato profondamente l'onesto barone di B.; ma a poco a poco egli se n'era dimenticato spensierandosi coll'amore e colla caccia: la gioia e la tranquillità erano rientrate nel castello; le livree verdi erano tornate a darsi buon tempo nelle anticamere; e non erano trascorsi due mesi dall'epoca di questo avvenimento che nè il barone, nè alcuno de' suoi domestici si ricordava della sparizione della fanciulla.

Era nel mese di novembre.

Un mattino, il barone di B. si svegliò un po' turbato da un cattivo sogno, si cacciò fuori del letto, spalancò la finestra, e vedendo che il cielo era sereno, e che i suoi limieri passeggiavano immalinconiti nel cortile e raspavano alla porta per uscirne, disse: «Voglio andare a caccia, io solo; vedo laggiù alcuni stormi di colombi selvatici che si son dati la posta nel seminato, e spero che ne salderanno il conto colle penne». Fatta questa risoluzione finì di abbigliarsi, infilzò i suoi stivali impenetrabili, si buttò il fucile ad armacollo, accomiatò le due livree verdi che lo solevano accompagnare ed uscì circondato da tutti i suoi limieri, i quali agitando la testa, facevano scoppiettare le loro larghe orecchie, e gli si cacciavano ad ogni momento tra le gambe accarezzando colle lunghe code i suoi stivali impenetrabili.

Il barone di B. si avviò direttamente verso il luogo ove aveva veduto posarsi i colombi selvatici. Era nell'epoca delle seminagioni, e nei campi arati di 
fresco non si scorgeva più un arbusto od un filo d'erba. Le pioggie dell'autunno avevano ammollito il terreno per modo che egli affondava nei solchi fino al ginocchio, e si vedeva ad ogni momento in pericolo di lasciarvi uno stivale. Oltre a ciò i cani, non assuefatti a quel genere di caccia, rendevano vana tutta la strategia del cacciatore, e i colombi avevano appostate qua e là le loro sentinelle avvanzate, precisamente come avrebbe fatto un bravo reggimento della vecchia guardia imperiale.

Stizzito da questa astuzia, il barone di B., continuò nondimeno a perseguitarli con maggiore accanimento, quantunque non gli venissero mai al tiro una sola volta; e sentivasi stanco e sopraffatto dalla sete, quando vide lì presso in un solco una pianticella rigogliosa di lamponi carica di frutti maturi.

— Strano! — disse il barone. — Una pianta di lamponi in questo luogo... e quanti frutti! Come sono belli e maturi!

E abbassando la focaia del fucile, lo collocò presso di sè, si sedette; e spiccando ad una ad una le coccole del lampone, i cui granelli di porpora parevano come argentati graziosamente di brina, estinse, come potè meglio, la sete che aveva incominciato a travagliarlo.

Stette così seduto una mezz'ora; in capo alla quale si accorse che avvenivano in lui dei fenomeni singolari.

Il cielo, l'orizzonte, la campagna non gli parevano più quelli; cioè non gli parevano essenzialmente mutati, ma non li vedeva più colla stessa sensazione di un'ora prima; per servirsi d'un modo di dire più comune, non li vedeva più cogli stessi occhi.

In mezzo a' suoi cani ve n'erano taluni che gli sembrava di non aver mai veduto, e pure riflettendoci bene, li conosceva; se non che li osservava e li accarezzava tutti quanti con maggior rispetto che non fosse solito fare: parevagli in certo modo che non ne fosse egli il padrone, e dubitandone quasi, si provò a 
chiamarli: Azor, Fido, Aloff! I cani chiamati gli si avvicinarono prontamente, dimenando la coda.

- Meno male, disse il barone, i miei cani sembrano essere proprio ancora i miei cani... Ma è singolare questa sensazione che provo alla testa, questo peso... E che cosa sono questi strani desideri che sento, queste volontà che non ho mai avute, questa specie di confusione e di duplicità che provo in tutti i miei sensi? Sarei io pazzo?... Vediamo, riordiniamo le nostre idee... Le nostre idee! Sì, perfettamente... perchè sento che queste idee non sono tutte mie. Però... è presto detto riordinarle! Non è possibile, sento nel cervello qualche cosa che si è disorganizzato, cioè... dirò meglio... che si è organizzato diversamente da prima... qualche cosa di superfluo, di esuberante; una cosa che vuol farsi posto nella testa, che non fa male, ma che pure spinge, urta in modo assai penoso le pareti del cranio... Parmi di essere un uomo doppio. Un uomo doppio! Che stranezza! E pure... sì, senza dubbio... capisco in questo momento come si possa essere un uomo doppio.

Vorrei sapere perchè questi anemoni mezzo fradici per le pioggie, ai quali non ho mai badato in vita mia, adesso mi sembrano così belli e così attraenti... Che colori vivaci, che forma semplice e graziosa! Facciamone un mazzolino.

E il barone, allungando la mano senza alzarsi, ne colse tre o quattro che, cosa singolare! si pose in seno come le femmine. Ma nel ritrarre la mano a sè, provò una sensazione ancora più strana; voleva ritrarre la mano, e nel tempo stesso voleva allungarla di nuovo; il braccio mosso come da due volontà opposte, ma ugualmente potenti, rimase in quella posizione quasi paralizzato.

- Mio Dio! disse il barone; e facendo uno sforzo violento uscì da quello stato di rigidità, e subito osservò attentamente la sua mano come a guardare se qualche cosa vi fosse rotto o guastato.

Per la prima volta egli osservò allora che le sue mani erano brevi e ben fatte, che le dita erano piene e fusolate, che le unghie descrivevano un elissi 
perfetto; e l'osservò con una compiacenza insolita; si guardò i piedi e vedendoli piccoli e sottili, non ostante la forma un po' rozza de' suoi stivali impenetrabili, ne provò piacere e sorrise.

In quel momento uno stormo di colombi si innalzò da un campo vicino, e venne a passargli d'innanzi al tiro. Il barone fu sollecito a curvarsi, ad afferrare il suo fucile, ad inarcarne il cane, ma... cosa prodigiosa! in quell'istante si accorse che aveva paura del suo fucile, che il fragore dello sparo lo avrebbe atterrito; ristette e si lasciò cader l'arma di mano, mentre una voce interna gli diceva: che begli uccelli! che belle penne che hanno nelle ali!... mi pare che sieno colombi selvatici...

- Per l'inferno! esclamò il barone portandosi le mani alla testa, io non comprendo più nulla di me stesso... sono ancora io, o non sono più io? o sono io ed un altro ad un tempo! Quando mai io ho avuto paura di sparare il mio fucile! Quando mai ho sentito tanta pietà per questi maledetti colombi che mi devastano i seminati? I seminati! Ma... veramente parmi che non sieno più miei questi seminati... Basta, basta, torniamo al castello, sarà forse effetto di una febbre che mi passerà buttandomi a letto.

$\mathrm{E}$ fece atto di alzarsi. Ma in quello istante un'altra volontà che pareva esistere in lui lo sforzò a rimanere nella posizione di prima, quasi avesse voluto dirgli: no, stiamo ancora un poco seduti.

Il barone sentì che annuiva di buon grado a questa volontà, poichè dallo svolto della via che fiancheggiava il campo era comparsa una brigata di giovani lavoratori che tornavano al villaggio. Egli li guardò con un certo senso di interesse e di desiderio di cui non sapeva darsi ragione; vide che ve ne erano alcuni assai belli; e quando essi gli passarono d'innanzi salutandolo, rispose al loro saluto chinando il capo con molto imbarazzo, e si accorse che aveva arrossito come una fanciulla. Allora sentì che non aveva più alcuna difficoltà ad alzarsi, e si alzò. Quando fu in piedi gli parve di essere più leggiero dello usato: 
le sue gambe parevano ora ingranchite, ora più sciolte; le sue movenze erano più aggraziate del solito, quantunque fossero poi in realtà le stesse movenze di prima, e gli paresse di camminare, di gestire, di dimenarsi, come aveva fatto sempre per lo innanzi.

Fece atto di recarsi il fucile ad armacollo, ma ne provò lo stesso spavento di prima, e gli convenne adattarselo al braccio, e tenerlo un poco discosto dalla persona, come avrebbe fatto un fanciullo timoroso.

Essendo arrivato ad un punto in cui la via si biforcava, si trovò incerto per quale delle due strade avrebbe voluto avviarsi al castello. Tutte e due vi conducevano del paro, ma egli era solito percorrerne sempre una sola: ora avrebbe voluto passare per una, e ad un tempo voleva passare anche per l'altra: tentò di muoversi, ma riprovò lo stesso fenomeno che aveva provato poc'anzi: le due volontà che parevano dominarlo, agendo su di lui colla stessa forza, si paralizzarono reciprocamente, resero nulla la loro azione: egli restò immobile sulla via come impietrato, come colpito da catalessi. Dopo qualche momento si accorse che quello stato di rigidità era cessato, che la sua titubanza era svanita, e svoltò per quella delle due strade che era solito percorrere.

Non aveva fatto un centinaio di passi che s'abbattè nella moglie del magistrato la quale lo salutò cortesemente.

- Da quando in qua, disse il barone di B., io sono solito a ricevere i saluti della moglie del magistrato?» Poi si ricordò che egli era il barone di B., che egli era in intima conoscenza colla signora, e si meravigliò di essersi rivolta questa domanda.

Poco più innanzi si incontrò in una vecchia che andava razzolando alcuni manipoli di rami secchi lungo la siepe.

- Buon dì, Caterina - le disse egli abbracciandola e baciandola sulle guancie, — come state? avete poi ricevuto notizie di vostro suocero? 


\section{Um espírito na framboesa}

Tradução do conto Uno spirito in un lampone, de Iginio Ugo Tarchetti

Rafael Ferreira da Silva

Davi de Sousa Barbosa

- Oh! Eccellenza... quanta degnazione... esclamò la vecchia, quasi spaventata dalla insolita famigliarità del barone, - le dirò...

Ma il barone l’interruppe dicendole: «Per carità, guardatemi bene, ditemi: sono ancora io? sono ancora il barone di B.?»).

— Oh, signore!... diss'ella.

Egli non stette ad attendere altra risposta, e proseguì la sua strada, cacciandosi le mani nei capelli, e esclamando: «Io sono impazzito, io sono impazzito».

Gli avveniva spesso lungo la via di arrestarsi a contemplare oggetti o persone che non avevano mai destato in lui il minimo interesse, e vedeali sotto un aspetto affatto diverso di prima. Le belle contadine che stavano sarchiando nei campi coll'abito rimboccato fin sopra il ginocchio, non avevano più per lui alcuna attrattiva, e le parevano rozze, sciatte e sguaiate. Gettando a caso uno sguardo su' suoi limieri che lo precedevano col muso basso e colla coda penzoloni, disse: «Tò! Visir che non aveva che due mesi adesso sembra averne otto suonati, e s'è cacciato anche lui nella compagnia dei cani scelti».

Mancavangli pochi passi per arrivare al castello quando incontrò alcuni de' suoi domestici che passeggiavano ciarlando lungo la via, e, cosa singolare! li vedeva doppî; provava lo stesso fenomeno ottico che si ottiene convergendo tutte e due le pupille verso un centro solo, per modo d'incrociarne la visuale; se non che egli comprendeva che le cause di questo fenomeno erano affatto diverse da quelle; poichè vedeali bensì doppî, ma non si rassomigliavano totalmente nella loro duplicità; vedeali come se vi fossero in lui due persone che guardassero per gli stessi occhi.

E questa strana duplicità incominciò da quel momento ad estendersi su tutti i suoi sensi; vedeva doppio, sentiva doppio, toccava doppio; e, - cosa ancora più sorprendente! - pensava doppio. Cioè, una stessa sensazione destava in lui due idee, e queste due idee venivano svolte da due forze diverse 
di raziocinio, e giudicate da due diverse coscienze. Parevagli in una parola che vi fossero due vite nella sua vita, ma due vite opposte, segregate, di natura diversa; due vite che non potevano fondersi, e che lottavano per contendersi il predominio de' suoi sensi — d'onde la duplicità delle sue sensazioni.

Fu per ciò che egli vedendo i suoi domestici, conobbe bensì che erano i suoi domestici; ma cedendo ad un impulso più forte, non potè a meno di avvicinarsi ad uno di essi, di abbracciarlo con trasporto e di dirgli: oh! caro Francesco, godo di rivedervi; come state? come sta il nostro barone? - e sapeva benissimo di essere egli il barone. - Ditegli che mi rivedrà fra poco al castello.

I domestici si allontanarono sorpresi; e quello tra loro che erane stato abbracciato, diceva tra sè stesso: io mi spezzerei la testa per sapere se è, o se non è veramente il barone che mi ha parlato. Io ho già inteso altre volte quelle parole... non so... ma quella espressione... quell'aspetto... quell'abbraccio... certo, non è la prima volta che io fui abbracciato in quel modo. E pure... il mio degno padrone non mi ha mai onorato di tanta famigliarità.

Pochi passi più innanzi, il barone di B. vide un pergolato che s'appoggiava ad un angolo del recinto d'un giardino, per modo che quando era coperto di foglie doveva essere affatto inaccessibile agli occhi dei curiosi. Egli non potè resistere al desiderio di entrarvi, quantunque vi fosse in lui un'altra volontà che l'incitava ad affrettarsi verso il castello. Cedette al primo impulso, e appena sedutosi sotto la pergola, sentì compiersi in sè stesso un fenomeno psicologico ancora più curioso.

Una nuova coscienza si formò in lui: tutta la tela di un passato mai conosciuto si distese d'innanzi a suoi occhi: delle memorie pure e soavi di cui egli non poteva aver fecondata la sua vita vennero a turbare dolcemente la sua anima. Erano memorie di un primo amore, di una prima colpa; ma di un amore più gentile e più elevato che egli non avesse sentito, di una colpa più dolce e più generosa che egli non avesse commesso. La sua mente spaziava in un mondo 
di affetti ignorato, percorreva regioni mai viste, evocava dolcezze mai conosciute.

Nondimeno tutto questo assieme di rimembranze, questa nuova esistenza che era venuta ad aggiungersi a lui, non turbava, non confondeva le memorie speciali della sua vita. Una linea impercettibile separava le due coscienze.

Il barone di B. passò alcuni momenti nel pergolato, dopo di che sentì desiderio di affrettarsi verso il villaggio. E allora le due volontà agendo su di esso collo stesso accordo, egli ne subì un impulso così potente che non potè conservare il suo passo abituale, e fu costretto a darsi ad una corsa precipitosa.

Queste due volontà incominciarono da quell'istante a dominarsi e a dominarlo con pari forza. Se agivano d'accordo, i movimenti della sua persona erano precipitati, convulsi, violenti; se una taceva, erano regolari; se erano contrarie, i movimenti venivano impediti, e davano luogo ad una paralisi che si protraeva fino a che la più potente di esse avesse predominato.

Mentre egli correva così verso il castello, uno de' suoi domestici lo vide, e temendo di qualche sventura, lo chiamò per nome. Il barone volle arrestarsi, ma non gli fu possibile; rallentò il passo e si fermò bensì per qualche istante, ma ne seguì una convulsione, un saltellare, un avanzarsi e un retrocedere a sbalzi per modo che sembrava invasato, e gli fu gioco forza continuare la sua corsa verso il villaggio.

Il villaggio non pareagli più quello, parevagli che ne fosse stato assente da molti mesi; vide che il campanile della parrocchia era stato riattato di fresco, e quantunque lo sapesse, gli sembrava tuttavia di non saperlo.

Lungo la strada si abbattè in molte persone che, sorprese di quel suo correre, lo guardavano con atti di meraviglia. Egli faceva a tutte di cappello, benchè comprendesse che nol doveva; e quelle rispondevangli togliendosi i loro berretti, e meravigliando di tanta cortesia. Ma ciò che sembrava ancora più singolare era che tutte quelle persone consideravano quasi come naturale quel 
suo correre, quel suo salutare; e pareva loro di aver travisto, intuito, compreso qualche cosa in que' suoi atti, e non sapevano che cosa fosse. Ne erano però impaurite e pensierose.

Giunto al castello si arrestò; entrò nelle anticamere; baciò ad una ad una le sue cameriere; strinse la mano alle sue livree verdi, e si buttò al collo di una di esse che accarezzò con molta tenerezza, e a cui disse parole come di passione e di affetto.

A quella vista le cameriere e le livree verdi fuggirono, e corsero urlando a rinchiudersi nelle loro stanze.

Allora il barone di B. salì agli altri piani, visitò tutte le sale del castello, e essendo giunto alla sua alcova, si buttò sul letto, e disse: «Io vengo a dormire con lei, signor barone.» In quell'intervallo di riposo, le sue idee si riordinarono, egli si ricordò di tutto ciò che gli era avvenuto durante quelle due ore, e se ne sentì atterrito; ma non fu che un lampo — egli ricadde ben presto nel dominio di quella volontà che lo dirigeva a sua posta.

Tornò a ripetersi le parole che aveva dette poc'anzi: «Io vengo a dormire con lei, signor barone.» E delle nuove memorie si suscitarono nella sua anima; erano memorie doppie, cioè le rimembranze delle impressioni che uno stesso fatto lascia in due spiriti diversi, ed egli accoglieva in sè tutte e due queste impressioni. Tali rimembranze però non erano simili a quelle che aveva già evocato sotto la pergola; quelle erano semplici, queste complesse; quelle lasciavano vuota, neutrale, giudice una parte dell'anima; queste l'occupavano tutta: e siccome erano rimembranze di amore, egli comprese in quel momento che cosa fosse la grande unità, l'immensa complessività dell'amore, il quale essendo nelle leggi inesorabili della vita un sentimento diviso fra due, non può essere compreso da ciascuno che per metà. Era la fusione piena e completa di due spiriti, fusione di cui l'amore non è che una aspirazione, e le dolcezze 


\section{Um espirito na framboesa \\ Tradução do conto Uno spirito in un lampone, de Iginio Ugo Tarchetti \\ Rafael Ferreira da Silva \\ Davi de Sousa Barbosa}

dell'amore un'ombra, un'eco, un sogno di quelle dolcezze. Nè potrei esprimere meno confusamente lo stato singolare in cui egli si trovava.

Passò così circa un'ora, scorsa la quale si accorse che quella voluttà andava scemando, e che le due vite che parevano animarlo si separavano. Discese dal letto, si passò le mani sul viso come per cacciarne qualche cosa di leggiero... un velo, un ombra, una piuma; e sentì che il tatto non era più quello; gli parve che i suoi lineamenti si fossero mutati, e provò la stessa sensazione come se avesse accarezzato il viso di un altro.

V'era lì presso uno specchio e corse a contemplarvisi. Strana cosa! Non era più egli; o almeno vi vedeva riflessa bensì la sua immagine, ma vedeala come fosse l'immagine di un altro, vedeva due immagini in una. Sotto l'epidermide diafana della sua persona, traspariva una seconda immagine a profili vaporosi, instabili, conosciuti. E ciò gli pareva naturalissimo, perchè egli sapeva che nella sua unità vi erano due persone, che era uno, ma che era anche due ad un tempo.

Allontanando lo sguardo dal cristallo, vide sulla parete opposta un suo vecchio ritratto di grandezza naturale, e disse: «Ah! questo è il signor barone di B.... Come è invecchiato!». E tornò a contemplarsi nello specchio.

La vista di quella tela gli fece allora ricordare che vi era nel corridoio del castello un'immagine simile a quella che aveva veduto poc'anzi trasparire dalla sua persona nello specchio, e si sentì dominato da una smania invincibile di rivederla. Si affrettò verso il corridoio.

Alcune delle sue cameriere che vi passavano in quell'istante furono prese da uno sgomento ancora più profondo di prima, e corsero fuggendo a chiamare le livree verdi che stavano assembrate nell'anticamera, concertandosi sul da farsi.

Intanto nel cortile del castello si era radunato buon numero di curiosi: la notizia delle follie commesse dal barone si era divulgata in un attimo nel 
villaggio, e vi aveva fatto accorrere il medico, il magistrato ed altre persone autorevoli del paese.

Fu deciso di entrare nel corridoio. Il disgraziato barone fu trovato in piedi d'innanzi ad un ritratto di fanciulla - quella stessa che era sparita mesi addietro dal castello - in uno stato di eccitamento nervoso impossibile a definirsi. Egli sembrava in preda ad un assalto violento di epilessia; tutta la sua vitalità pareva concentrarsi in quella tela; pareva che vi fosse in lui qualche cosa che volesse sprigionarsi dal suo corpo, che volesse uscirne per entrare nell'immagine di quel quadro. Egli la fissava con inquietudine, e spiccava salti prodigiosi verso di lei, come ne fosse attratto da una forza irresistibile.

Ma il prodigio più meraviglioso era che $i$ suoi lineamenti parevano trasformarsi, quanto più egli affissava quella tela, ed acquistare un'altra espressione. Ciascuna persona riconosceva bensì in lui il barone di B., ma vi vedeva ad un tempo una strana somiglianza coll'immagine riprodotta nel quadro. La folla accorsa nel corridoio si era arrestata compresa da un panico indescrivibile. Che cosa vedevano essi? Non lo sapevano: sentivano di trovarsi d'innanzi a qualche cosa di soprannaturale.

Nessuno osava avvicinarsi, - nessuno si moveva; - uno spavento insuperabile si era impadronito di ciascuno di essi; un brivido di terrore scorreva per tutte le loro fibre...

Il barone continuava intanto ad avventarsi verso il quadro; la sua esaltazione cresceva, i suoi profili si modificavano sempre più, il suo volto riproduceva sempre più esattamente l'immagine della fanciulla... e già alcune persone parevano voler prorompere in un grido di terrore, quantunque uno spavento misterioso li avesse resi muti od immobili, allorchè una voce si sollevò improvvisamente dalla folla che gridava: «Clara! Clara!».

Quel grido ruppe l'incantesimo. «Sì, Clara! Clara!» ripeterono unanimi le persone radunate nel corridoio, precipitandosi l'una sull'altra verso le porte, 


\section{Um espirito na framboesa \\ Tradução do conto Uno spirito in un lampone, de Iginio Ugo Tarchetti \\ Rafael Ferreira da Silva \\ Davi de Sousa Barbosa}

sopraffatte da un terrore ancora più grande, e quel nome era il nome della fanciulla sparita dal castello, la cui immagine era stata riprodotta dalla tela.

Ma a quella voce, il barone di B. si spiccò dal quadro e si slanciò in mezzo alla folla gridando: «Il mio assassino, il mio assassino!». La folla si sparpagliò e si divise. Un uomo era in terra svenuto - quello stesso che aveva gridato, - il giovane guardaboschi su cui pendevano sospetti per la sparizione misteriosa di Clara.

Il barone di B. fu trattenuto a forza dalle sue livree verdi. Il guardaboschi rinvenuto domandò del magistrato, cui confessò spontaneamente di aver uccisa la fanciulla in un eccesso di gelosia, e di averla sotterrata in un campo, precisamente in quel luogo dove, poche ore innanzi, aveva veduto lo sfortunato barone sedersi e mangiare le coccole del lampone.

$\mathrm{Fu}$ data subito al barone di B. una forte dose di emetico che gli fece rimettere i frutti non digeriti, e lo liberò dallo spirito della fanciulla.

Il cadavere di essa, dal cui seno partivano le radici del lampone, fu dissotterrato e ricevette sepoltura cristiana nel cimitero.

Il guardaboschi, tradotto in giudizio, ebbe condanna a dodici anni di lavori forzati.

Nel 1865 io lo conobbi nello stabilimento carcerario di Cosenza che mi era recato a visitare. Mancavangli allora due anni a compiere la sua pena; e fu da lui stesso che intesi questo racconto meraviglioso.

\section{Referências}

TARCHETTI, Iginio Ugo. Uno spirito in un lampone. In TARCHETTI, Iginio. Racconti fantastici. Milano: Treves, 1869, 115-136. Disponível em $<$ shorturl.at/dfDX1>. Acesso em 01/07/2020.

Racconti fantastici, Pensieri. Milano: E. Treves e C. editori, 1869. 